\title{
Resting State Functional Connectivity Magnetic Resonance Imaging
}

National Cancer Institute

\section{Source}

National Cancer Institute. Resting State Functional Connectivity Magnetic Resonance

Imaging. NCI Thesaurus. Code C129326.

A technique that monitors blood oxygen level dependent (BOLD) signals to map brain regions that active while not performing any specific task. 